\title{
Impact of the COVID-19 lockdown on screen media use in patients referred for ADHD to child and adolescent psychiatry: an introduction to problematic use of the internet in ADHD and results of a survey
}

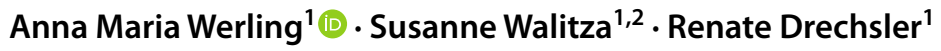

Received: 30 November 2020 / Accepted: 25 March 2021 / Published online: 22 April 2021

(c) The Author(s) 2021

\begin{abstract}
The COVID-19 outbreak and lockdown have been associated with multiple consequences for mental health, including an excessive and potentially harmful increase in screen media use. The specific consequences for children, adolescents and young adults with ADHD are still unknown. In the first part of this study, a short review of problematic use of the internet (PUI) in ADHD is presented, showing that patients with ADHD are at risk for different aspects of PUI, such as excessive gaming or problematic social media use. In the second part, we report original data of an online survey on screen media use before, during and after the lockdown completed by parents of children and adolescents clinically referred for ADHD. Parents rated children's/adolescents' media-related behavior and media time on a new screening questionnaire for PUI. Each item was rated three times, referring to the observed behavior before, during and 1-2 months after the lockdown. $N=126$ parents of patients referred for ADHD aged 10-18 years participated in the study. Total media time increased by $46 \%$ during the lockdown and did not completely return to pre-Corona levels afterwards. Patients with difficulties concentrating, high irritability or deterioration of ADHD problems under lockdown spent more time with screen media than those with milder or no such problems. While the effects of the lockdown on screen media use and its negative impact on everyday life appear to be largely reversible, a small proportion of patients with ADHD apparently continue to show increased media use.
\end{abstract}

Keywords Attention deficit hyperactivity disorder · Problematic use of the internet · COVID-19 · Adolescents · Gaming · Social media

\section{Introduction}

The COVID-19 pandemic is occurring in a new technological and social context, with an apparently endless and immediate access to the internet (Chen et al. 2020; Guessoum et al. 2020; Moreno et al. 2020). Health care professionals have thus raised concerns especially regarding problematic media use in children and adolescents (King et al. 2020; Király et al. 2020; Ko et al. 2020; Montag et al. 2020). In

\section{Anna Maria Werling}

anna.werling@pukzh.ch

1 Department of Child and Adolescent Psychiatry and Psychotherapy, Centre for Child and Adolescent Psychiatric Research, Neuropsychology, University Hospital of Psychiatry Zurich, University of Zurich, Eisengasse 16, 8008 Zurich, Switzerland

2 Neuroscience Center Zurich, University of Zurich and ETH Zurich, Zurich, Switzerland the general population, a dramatic increase of media use in adolescents is already reported (Thomasius 2020). However, the specific consequences for children and adolescents with Attention Deficit Hyperactivity Disorder (ADHD) in particular (Cortese et al. 2020) and on their media usage are not well known.

First publications on general mental and behavioral consequences of the pandemic have reported that under lockdown, children and adolescents with ADHD showed inflated conduct problems (Nonweiler et al. 2020), problems with remote learning (Becker et al. 2020), often worsened (Zhang et al. 2020), but sometimes also improved behavioral symptoms (Bobo et al. 2020). An Australian study reported increased media usage (gaming, TV, social media) along with positive and negative life style changes under lockdown for children and adolescents with ADHD (Sciberras et al. 2020). To which extent these changes may be permanent or transitory after the release of measures has not been investigated before. 
In the first part of this study, a short introduction to aspects of problematic use of the internet (PUI) is given, with a focus on their relevance for ADHD. ADHD is considered to be one of the main comorbidities of PUI (Ho et al. 2014); inversely, ADHD is associated with a higher prevalence of PUI (Chen et al. 2015; Bioulac et al. 2008; Enagandula et al. 2018; Ha et al. 2006; Wang et al. 2017). In the second part of this publication, a survey with parents of patients referred for ADHD to child and adolescent psychiatry will be presented. In this survey, started after the spring lockdown 2020, we asked about changes in media time and problematic internet behaviors before, during and after the lockdown.

\section{Problematic internet use and ADHD}

Problematic internet use (PUI) represents a broader, multifaceted field of problems related to internet use with similarity to impulse control disorders (Carli et al. 2013; Ioannidis et al. 2018; Shapira et al. 2000; Young 1998b). It refers to the inability to control one's usage of the internet, resulting in dysfunctional patterns (e.g., excessive gaming, excessive use of social networks, excessive viewing of video clips etc.) with major negative consequences for interpersonal relationships, academic performance, and emotional well-being (Kubey et al. 2001; Liu et al. 2007; Spada 2014; Young 1998a; Yu et al. 2013). Besides excessive use and addictive aspects, PUI is also linked to other risky online behaviors, such as cyberbullying (Gámez-Guadix et al. 2016; Machimbarrena et al. 2018). Despite the evolving body of research on PUI, consensus on diagnostic criteria is lacking (Christakis et al. 2009; Ioannidis et al. 2018; Ko et al. 2005; Shapira et al. 2003), leading to inconsistencies in reported prevalence rates of PUI, ranging from 1 to 38\% (Leung 2004; Rehbein et al. 2015; Vigna-Taglianti et al. 2017). An association between PUI and ADHD (Restrepo et al. 2020) or elevated media use and ADHD-related behaviors, respectively, has been frequently reported (e.g., Ceranoglu 2018; Nikkelen et al. 2014; Wang et al. 2017). The most consistent associations between ADHD symptoms and PUI have been found with impulsivity, and less with inattention and hyperactivity (El Asam et al. 2019; Kaess et al. 2014; Rosen et al. 2014).

\section{(Internet) Gaming disorder and ADHD}

Gaming is considered as a continuum from harmless leisure activity to excessive use, with impairment and distress resulting in pathological or addiction-like behavior (Grüsser et al. 2006; Paulus et al. 2018). Gaming disorder (GD), as the best-studied domain in addictive online behaviors (Fauth-Bühler et al. 2017), has recently been included in the ICD-11 (King et al. 2019; WHO 2016; Yao et al. 2017). Internet Gaming Disorder (IGD) has been included in the
DSM-5 (APA 2013), with diagnostic criteria matching those for substance use disorders (APA 2013; Petry et al. 2014; Rehbein et al. 2015). Prevalence rates of IGD range between 1 and $15 \%$, depending on sample characteristics, age and country (Durkee et al. 2012; Gentile et al. 2017; Paulus et al. 2018). Individuals with IGD/GD share neurobiological alterations typical for ADHD, such as in brain regions associated with dopamine-mediated reward mechanisms (Weinstein et al. 2020), reduced activity in impulse control areas, and dysfunction in the prefrontal cortex (Brand et al. 2016; Rubia 2018).

Clinical or epidemiological studies have reported associations between IGD/ GD and ADHD symptoms (Stavropoulos et al. 2019), and in children and adolescents the severity of ADHD symptoms has been shown to correlate with problematic gaming (Chan et al. 2006; Paulus et al. 2018). Although addiction-like behaviors in PUI are usually linked to impulsivity in the literature (El Asam et al. 2019; Kaess et al. 2014; Rosen et al. 2014), a recent meta-analysis reported a stronger association between problematic gaming and inattention symptoms in ADHD (Mazurek et al. 2013). In sum, ADHD is both a comorbidity of IGD/GD and a risk factor for IGD/ GD (Ko et al. 2009) or problematic gaming (Carli et al. 2013). It has been stated that gaming could be a form of self-medication (Han et al. 2009), and a mean for coping with stress (Jones et al. 2014), or for escaping from everyday problems and distress (Snodgrass et al. 2014), which may contribute to the high rate of gaming in individuals with ADHD.

\section{Social media use and ADHD}

Due to its high prevalence, social media use (SMU) is considered as normative behavior (Settanni et al. 2018). Addictive SMU, in contrast, is defined as a compulsive need and excessive preoccupation with social media, while other aspects of life such as relationships, school, and mental health related behaviors (sports, eating regularly and balanced, day-night rhythm including adequate sleep duration) are neglected and impaired [e.g., (Frost et al. 2017; Karaiskos et al. 2010; Lenhart et al. 2010)]. Prevalence among adolescents estimates vary, ranging from 4.5 to 43.2\% (Bányai et al. 2017; Gul et al. 2018; Van Den Eijnden et al. 2016), with a higher prevalence in girls (Rumpf et al. 2014; Andreassen et al. 2012) and with growing mental health problems (Mérelle et al. 2017; Rosenberg et al. 2014).

Since SMU exerts positive short-term effects on mood, it is not surprising that adolescents with ADHD are more prone to SMU addiction (Barry et al. 2017) than nonaffected controls. In addition, adolescents with ADHD may be especially attracted to SMU as they are more sensitive to external distractors (Cassuto et al. 2013). Students with higher ADHD symptoms are more likely to report high 
levels of addictive Facebook use (Settanni et al. 2018) and inversely, elevated SMU may also increase ADHD symptoms in adolescents (Boer et al. 2020; Cabral 2008).

\section{Cyberbullying and ADHD}

Cyberbullying is defined as an intentional act to use electronic communication to embarrass or humiliate another person (Heiman et al. 2015; Kowalski et al. 2012; Kowalski et al. 2013). Higher rates of cyberbullying seem to result from difficulties with social interaction and impulsive and aggressive behavior, which is often seen in individuals with ADHD (Harty et al. 2009; Tokunaga 2010). Due to impaired or less developed social skills in individuals with ADHD (Shea et al. 2003), internet and social media provides a potential space for social contacts with peers while simultaneously likely leading to cyberbullying (Didden et al. 2009). Thus, individuals with ADHD seem to be at increased risk for cyberbullying as perpetrators (boys) or victims (girls) (Bacchini et al. 2008; Dawson et al. 2019; Gorucu Aydin et al. 2020).

\section{Problematic internet use, ADHD and therapy}

To date, relatively few studies have investigated different treatment options for PUI and related disorders, even less for comorbid PUI and ADHD [e.g., (Chang et al. 2020)]. Although IGD is considered a treatable disorder, strong conclusions regarding treatment efficacy are lacking (Zajac et al. 2020). Cognitive behavioral therapy has received the largest evidence base for PUI (Spada 2014; Young 2007). Pharmaceutical agents such as methylphenidate (Han et al. 2009), escitalopram (Dell'Osso et al. 2008), citalopram (Sattar et al. 2004) and olanzapine (McElroy et al. 2008) or bupropion (Zajac, Ginley, and Chang 2020) have also been tested with some positive findings, but cognitive-behavioral therapy is established as the first choice therapy for internet addiction (Young 2011) or IGD (Stevens et al. 2019).

\section{Problematic internet use (PUI) in adults with ADHD}

Most studies on PUI in adult ADHD have targeted young adults, often college students, in Asia, especially China, South Korea and Japan, where the prevalence of PUI is known to be much higher than in Western countries (Darvesh et al. 2020; Stavropoulos et al. 2020). A metaanalysis (Wang et al. 2017) reports similar prevalence rates of ADHD in adolescents ( $<18$ years) or young adults $(>18$ years) with internet addiction. In a large scale survey with Chinese college students (aged 17-25 years), the total prevalence of internet addiction was $7.21 \%$ in male and $8.17 \%$ in females, and ADHD was a risk factor both for male and female internet addiction (male OR 6.487, female OR
4.497) (Shen et al. 2020). The association between ADHD characteristics and PUI has also been reported in others cultures: In a large cross sectional study with over 22,000 adult participants (mean age 35.8 years) (Andreassen et al. 2016), ADHD was stronger positively associated with addictive social networking than with online gaming, and both were related to lower adult age. Other studies also point towards an association between PUI, ADHD symptoms and lower adult age, e.g., between smartphone addiction and ADHD inattention symptoms (Panagiotidi et al. 2018), while PUI in older adults seems more often related to OCD or depression (Ioannidis et al. 2018).

\section{Online survey on screen media use before, during and after the COVID-19 lockdown}

\section{Goals of the study}

In the following section, the results of an online survey conducted with parents of children and adolescents referred to child and adolescent psychiatry for ADHD are reported. Patients with ADHD are known to be particularly at risk for PUI. The goals of the study were to investigate (1) the impact of the lockdown on media use, especially on media time, as well as on risky online behaviors in patients referred for ADHD to child and adolescent psychiatry. (2) We wanted to investigate possible associations between the use of digital media and behavioral or emotional problems under the lockdown. (3) Finally, we intended to investigate the course of media-related behavior after the release of measures. Although we hypothesized to find a sizable increase of media time under the lockdown, we could not project whether we had to expect a chronification of media overuse, such as apprehended by some mental health specialists [e.g., (Király et al. 2020)], or would rather find a "back to normal" after the release of measures.

\section{Method}

\section{Recruitment, procedure and timeline}

Parents of patients aged between 10 and 18 years, who had been referred during the last 2 years to an outpatient clinic of the Department of Child and Adolescent Psychiatry and Psychotherapy (CAPP), University of Zurich, Switzerland, were invited to participate in an anonymous online survey. Invitations to participate and a link to access the survey were sent to parents of all patients of the defined time frame by email. The questions were to be completed by one parent. Data collection started in the last week of May 2020 and ended in the first week of July 2020. In Switzerland, a complete lockdown with homeschooling and onsite school 
closure began on March 16th, and a first easing of measures occurred on the 26th April. The first schools reopened on May 11th. At the time of the survey, in June 2020, most students had returned to classes, at least part time (Table 1).

The study was conducted in accordance with the principles of the declaration of Helsinki and with the regularities of the local Ethics committee.

\section{Instruments}

The survey consisted of two parts: an adapted version of a new PUI-screening ("PUI-Screening Questionnaire for Children and Adolescents" (PUI-SQ); Werling et al., submitted) developed for the routine screening of PUI in child and adolescent psychiatry, and the European CoRonavIruS Health Impact Survey 3.2 (CRISIS) of the ECNP group, which was developed to assess mental health problems and well-being of patients and their parents during the COVID-19 crisis, and will be analyzed elsewhere. The present study focuses on screen media related behavior assessed by the PUI-SQ. However, basic information on demographic data, psychopathological symptoms and PUI-relevant aspects of psychological well-being were drawn from the CRISIS 3.2 questionnaire.

The PUI-SQ was conceived as a paper-and-pencil instrument for problematic internet use and screen-media related problems in clinically referred children and adolescents. We present the results of a shortened version comprising the following subscales:
- Negative impact subscale: Impact of media use on everyday life and addiction-like behaviors (seven items)

- Digital risks and problems subscale: Parents' concern about problem behavior and risks related to media use (eight items)

- Media time: Amount of time per day (during leisure time) spent on different digital activities (gaming, social media) and with different devices (mobile/smartphone, PC/tablet, gaming console, TV) (six items)

For the present study, each item had to be rated three times on a 4-point Likert scale (from "not true" to "absolutely true"): regarding the behavior (1) retrospectively before the Corona crisis (Time 1: January/February 2020), (2) during the lockdown (Time 2: March/April 2020), and 3. after the lockdown (Time 3: "last two weeks", May/ June2020). The estimated media time was indicated on a 5-point rating scale ("no time", "less than $1 \mathrm{~h}$ ", 1-3 h", 4-6 h", "more than 6 h").

\section{Statistical analysis}

Parents' item responses were analyzed descriptively. Interval scaled data were analyzed by ANOVA (or repeated measures ANOVA). For PUI-SQ subscales 2 and 3, scores were calculated. For statistical comparison, responses on time duration spent with media were recoded using the medium value of each time range category as a numerical value (i.e., $1 / 2 \mathrm{~h}$, $2 \mathrm{~h}, 5 \mathrm{~h}$, and $7 \mathrm{~h}$; the latter as a conservative estimate for the category $>6 \mathrm{~h}$ ). Estimated total media time was calculated by adding up the time durations for all devices (smartphone,

Table 1 Sample description: demographics and comorbidities

\begin{tabular}{|c|c|c|c|c|c|c|}
\hline & $N$ & $\%$ & Age mean & SD & Age range & Ratio $\mathrm{m} / \mathrm{f}$ \\
\hline All & 126 & 100 & 13.21 & 2.29 & $10-18$ & $94 / 32$ \\
\hline Age $\leq 13$ years & 66 & $52.4 \%$ & 11.31 & 1.09 & $10-13$ & $47 / 19$ \\
\hline Age $\geq 14$ years & 60 & $47.6 \%$ & 15.32 & 1.21 & $14-18$ & $47 / 13$ \\
\hline Male & 94 & $74.6 \%$ & 13.14 & 2.37 & $10-18$ & \\
\hline Female & 32 & $25.4 \%$ & 13.50 & 2.17 & $10-18$ & \\
\hline \multicolumn{7}{|l|}{ Comorbidities } \\
\hline None & 75 & $50.5 \%$ & 13.27 & 2.29 & $10-18$ & $59 / 16$ \\
\hline Learning disorder & 20 & $15.9 \%$ & 12.86 & 2.47 & $10-16$ & $13 / 7$ \\
\hline Depression & 6 & $4.7 \%$ & 14.17 & 2.48 & $11-17$ & $4 / 2$ \\
\hline Anxiety & 5 & $4.0 \%$ & 11.00 & 1.22 & $10-13$ & $4 / 1$ \\
\hline Eating disorder & 4 & $3.2 \%$ & 15.25 & 2.06 & $13-17$ & $1 / 3$ \\
\hline Other & 16 & $12.7 \%$ & 13.90 & 2.33 & $10-18$ & $13 / 3$ \\
\hline \multicolumn{7}{|l|}{ School } \\
\hline \multicolumn{2}{|c|}{$\begin{array}{l}\text { School situation of Same as January } \\
\text { the last } 2 \text { weeks } \quad 2020\end{array}$} & $\begin{array}{l}\text { Single days/part } \\
\text { time at school }\end{array}$ & Online, some hours & $\begin{array}{l}\text { Online, regular } \\
\text { school hours }\end{array}$ & $\begin{array}{l}\text { Other/ not appli- } \\
\text { cable }\end{array}$ & \\
\hline$\%$ Responses & $56.3 \%$ & $37.3 \%$ & $4.0 \%$ & $1.6 \%$ & 0.8 & \\
\hline
\end{tabular}

$\mathrm{SD}=$ standard deviation. Deviations from $100 \%$ may be due to rounding 
tablet/PC, game console, TV). When distributional assumptions were not met, ANOVAs, which are known to be robust against violations (Blanca et al. 2017), were nevertheless used, Greenhouse-Geisser corrections were reported and post-hoc pairwise analyses were performed by nonparametric tests and Bonferroni-corrected.

\section{Results}

\section{Participants}

The present sample of $N=126$ patients referred for ADHD to the Department of child and adolescent psychiatry (CAPP) is drawn from a larger sample of patients with all types of psychopathologies, whose parents responded to the survey. The response rate of all parents was approximately $28 \%$. All information was collected anonymously and diagnostic classification was based entirely on self-assessments: Parents were asked to indicate the main psychopathological problem for which their child had been referred to the CAPP, by selecting among psychopathological categories or by specifying the nature of the problem in a free text section. Parents could indicate a second problem in a subsequent question. The present sample includes participants who indicated ADHD as the main psychopathological problem (Table 1). Patients with autism spectrum disorder as second problem were excluded. Girls were underrepresented in this sample with a ratio of $1: 3$, which is approximately representative of the ADHD gender distribution in a clinically referred population at this age.

\section{Time spent with media}

Media consumption increased considerably during the lockdown (Fig. 1a). Smartphone use over $4 \mathrm{~h}$ per day increased from $15 \%$ of patients before the Corona crisis to $36 \%$ under lockdown, tablet/PC use from 2 to $22 \%$ and gaming console use from 3 to $11 \%$. Excessive TV use under lockdown (over $6 \mathrm{~h}$ ) was not reported, but a small group (4\%) began to watch $\mathrm{TV}$ for more than $4 \mathrm{~h}$ per day. Adolescents (14-18 years) spent considerably more time on gaming and with social media under lockdown than did children (10-13 years) (Fig. 1b). The percentage of patients who spent more than $4 \mathrm{~h}$ on gaming increased from 6 to $23 \%$ in adolescents and from 0 to $17 \%$ in children. Likewise, the proportion of social media time use over $4 \mathrm{~h}$ increased from 10 to $24 \%$ in adolescents and from 2 to $11 \%$ in children.

It is worthy of mention that girls showed a slightly different pattern of use, with high social media time (over $4 \mathrm{~h}$ : $28 \%, N=9$ ) but low gaming time (over 4 h: $3 \%, N=1$; no gaming: $53 \%, N=17$ ) under lockdown. However, due to the small number of female patients, we did not analyze gender differences further.
Fig. 1 Hours per day during leisure time spent with screen media/the internet before the Corona crisis (before LD), during lockdown (during LD) and after lockdown (after LD = "last 2 weeks"). a Screen media devices: Hours per day spent with smartphone, tablet/PC, game console or TV $(N=126)$. b Digital Activities: Hours per day spent with gaming and social media in children $(10-13$ years, $N=66)$ and adolescents $(14-18$ years, $N=60$ ). Numbers refer to percent of responses

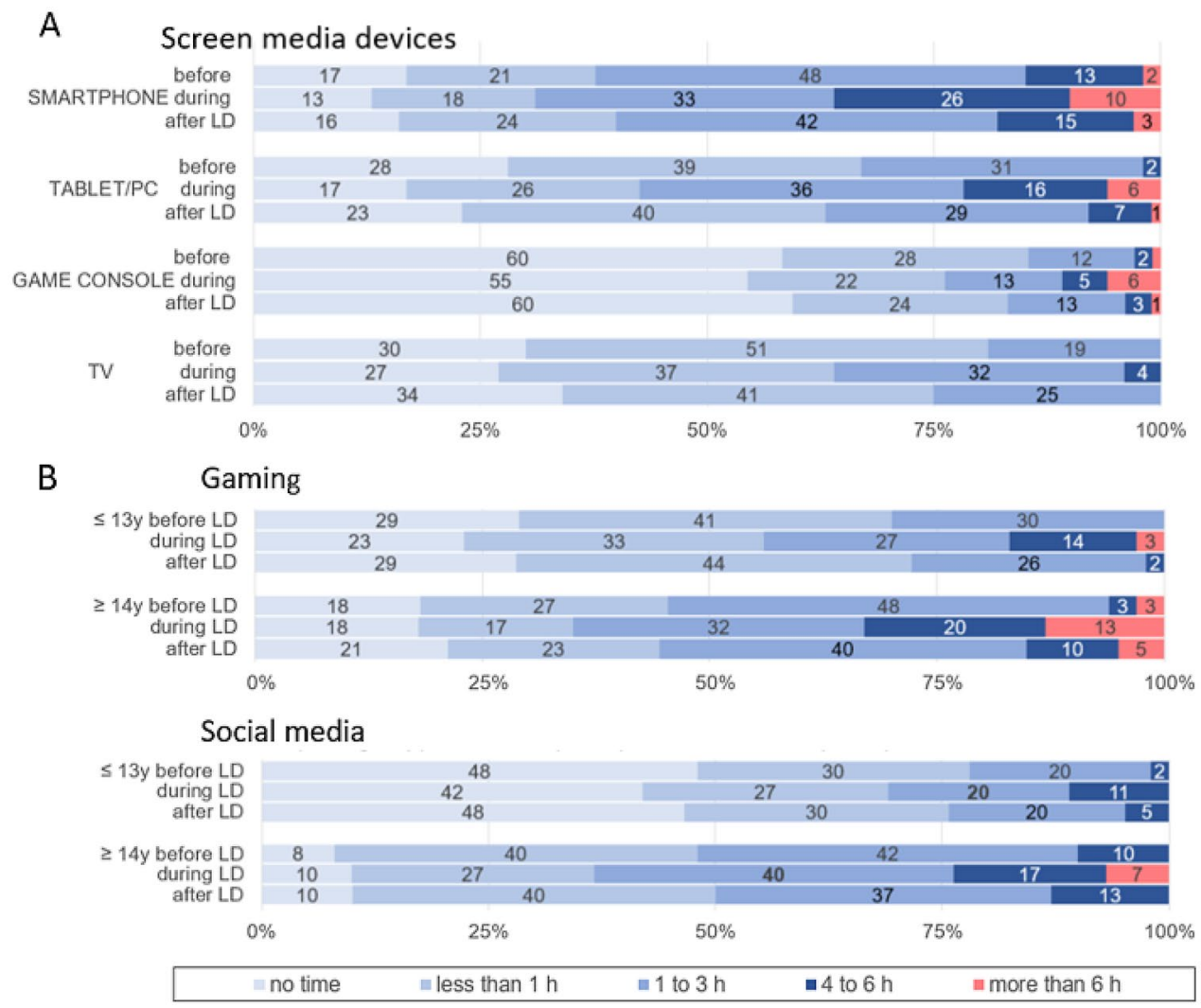


The comparison of estimated total media time (eTMT) over time for the full group, resulted in a significant increase from pre-Corona to lockdown (T1-T2), followed by a significant decrease after the easing of lockdown measures ("last 2 weeks") (T2-T3) (Fig. 2) $(F(1.425,179)=81.144$, $p<0.001)$. Nevertheless, eTMT did not completely return to pre-Corona levels at T3 $((Z=-3.448), p<0.001)$, but remained significantly higher (Fig. 2). In the full group, repeated measures analyses did not reveal different effects or interactions regarding age groups over time

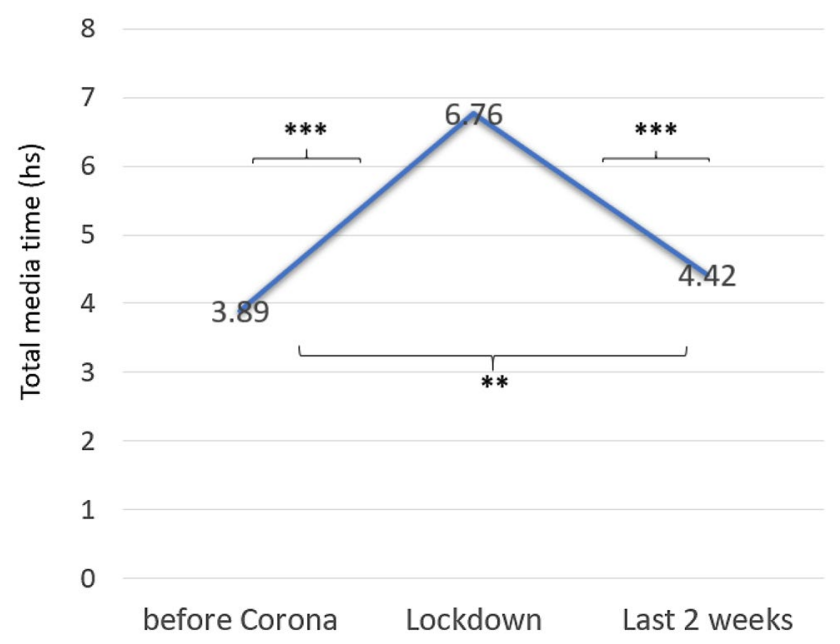

Fig. 2 Mean estimated total media time (hours) in patients with ADHD before, during and after the lockdown $(N=126)$. $* * p<0.01$, $* * * p<0.001$
$(F(1.425,179)=2.272, p<0.122)$, while between-group effects showed that adolescents had considerably higher eTMT than did children $(F(1,124)=22.245, p<0.001)$ (during lockdown: adolescents mean eTMT $=8.39 \mathrm{~h}$, children mean eTMT $=5.29 \mathrm{~h}$ ).

\section{Negative impact of media use before and under lockdown}

A moderate to severe negative impact of screen media use on everyday life aspects before Corona was reported by $15 \%$ (mental health) to $32 \%$ (family life) of parents (Table 2). Under lockdown, the negative impact on family life increased in $29 \%$, with a total of $46 \%$ of parents reporting a major negative impact (30.2\% slightly true, $15.9 \%$ absolutely true). Moderate to high concern about aggressive reactions and secret media use were already very common before Corona and these concerns increased relatively little under lockdown: from 46 to $50 \%$ of parents who described a major concern about aggressiveness, and from 34 to $40.5 \%$ about secret media use. $6.3 \%$ of parents stated that they had no agreement with their child regarding media time, which may be explained by the high mean age in this small group $(N=8$, mean age 16.0 years). The negative impact subscale score increased significantly from pre-Corona (T1) (mean 13.90, SD 4.7) to lockdown (T2) (mean 15.38, SD 5.83; $\mathrm{T} 1: \mathrm{T} 2 Z=-3.819, p<0.001)$, and subsequently decreased from lockdown (T2) to "last 2 weeks" (T3: mean 14.34, SD $5.47, Z=-3.81, p<0.001)$. Differences between T1 and T3 were only not significant anymore after Bonferroni correction $(\alpha=0.016 ; Z=-2.356, p<0.018)$. Thus, taken together,

Table 2 Negative impact of media use before and during the lockdown

\begin{tabular}{|c|c|c|c|c|c|c|c|c|}
\hline \multirow[b]{2}{*}{ Negative impact of child's media use on... } & \multicolumn{4}{|c|}{ Before Corona (T1) } & \multicolumn{2}{|c|}{$\begin{array}{l}\text { Lockdown } \\
\text { (T2) compared } \\
\text { to } \mathrm{T} 1\end{array}$} & \multicolumn{2}{|c|}{$\begin{array}{l}\text { Last } 2 \text { weeks } \\
\text { (T3) compared } \\
\text { to } \mathrm{T} 2\end{array}$} \\
\hline & Not true & Slightly true & Quite true & Absolutely true & Worse & Better & Better & Worse \\
\hline ...family life & $20 \%$ & $49 \%$ & $27.0 \%$ & $5 \%$ & $29 \%$ & $8.2 \%$ & $23 \%$ & $7 \%$ \\
\hline ...homework and academic achievements & $34 \%$ & $42 \%$ & $20 \%$ & $4 \%$ & $26 \%$ & $9 \%$ & $18 \%$ & $8 \%$ \\
\hline ...friendships and social activities in real life & $52 \%$ & $33 \%$ & $14 \%$ & $2 \%$ & $23 \%$ & $5 \%$ & $18 \%$ & $6 \%$ \\
\hline ...mental well-being and mental health (e.g., mood) & $36 \%$ & $48 \%$ & $14 \%$ & $1 \%$ & $18 \%$ & $6 \%$ & $14 \%$ & $6 \%$ \\
\hline \multirow{2}{*}{...physical well-being and health (e.g., sleep) } & $45 \%$ & $36 \%$ & $18 \%$ & $2 \%$ & 23.6 & $7.0 \%$ & $14.9 \%$ & $6.5 \%$ \\
\hline & \multicolumn{4}{|c|}{ Before Corona (T1) } & \multicolumn{2}{|c|}{$\begin{array}{l}\text { Lockdown } \\
\text { (T2) compared } \\
\text { to } \mathrm{T} 1\end{array}$} & \multicolumn{2}{|c|}{$\begin{array}{l}\text { Last } 2 \text { weeks } \\
\text { (T3) compared } \\
\text { to T2 }\end{array}$} \\
\hline \multirow[t]{2}{*}{ I am concerned because my child ... } & Not true & Slightly true & Quite true & Absolutely true & \multicolumn{2}{|c|}{ Concern } & \multicolumn{2}{|c|}{ Concern } \\
\hline & & & & & More & Less & More & Less \\
\hline $\begin{array}{l}\text {...becomes aggressive/very angry when media use } \\
\text { is restricted }\end{array}$ & $23 \%$ & $31 \%$ & $32 \%$ & $14 \%$ & $19 \%$ & $6 \%$ & $5 \%$ & $16 \%$ \\
\hline $\begin{array}{l}\text {... secretly spends more time with media than agreed } \\
\text { upon }^{\mathrm{a}}\end{array}$ & $32 \%$ & $29 \%$ & $24 \%$ & $10 \%$ & $28 \%$ & $7 \%$ & $5 \%$ & $19 \%$ \\
\hline
\end{tabular}

${ }^{a}$ Not applicable/no agreement was made between parents and child: $6 \%$ 
it can be concluded that negative effects of screen media use on everyday life significantly increased under lockdown, but these effects were mostly reversible and returned in part to pre-Corona values once lockdown measures were eased.

\section{Specific risks and problems}

On the specific problem and risks subscale, the majority of parents indicated no or only minor concern (Table 3). A comparison of pre-Corona and lockdown subscale scores did not yield significant differences $(\mathrm{T} 1$ mean $=10.01$, SD 3.0; T2 mean $=10.11$, SD 3.2; $Z=-0.960 ; p<0.339)$, demonstrating that specific or risky problem behavior was not induced or changed by the lockdown situation. Therefore, we only report lockdown results here (Table 3). Adolescents' subscale scores were significantly higher than those of children (10.66, SD 2.80 vs. 9.60, SD 3.49; $Z=-2.919$, $p<0.004)$. with the largest differences between adolescents and children being found regarding a major concern (responses slightly true and absolutely true) about the use of problematic or violent video games (13.3\% compared to $6 \%$ ) and the careless or risky handling of personal data and. information (16.6\% compared to $4.5 \%)$. In both age groups, the frequency of major concern about cyberbullying was low (5\% vs. $7.6 \%)$.

\section{Relation between total media time and ADHD related problems under lockdown}

Four items of the CRISIS 3.2 questionnaire were directly be related to ADHD symptoms: an item asking parents whether the main psychopathological problem (that is ADHD) had changed, and three items asking about irritable, hyperactive/restless or unfocused/unconcentrated behavior during the lockdown. All answers were rated on 5-point Likert scales. We investigated whether these ratings of symptoms characteristic for ADHD could be related to the total time spent with media under lockdown. $46.8 \%$ of parents $(N=59)$ reported no change of the main psychopathological problem, 33.3\% $(N=42)$ an improvement and $19.8 \%(N=25)$ a deterioration. Patients with a deterioration of ADHD symptoms had significantly longer media times (eTMT $=9.5 \mathrm{~h}$, SD 5.23) than those with an improvement (eTMT $=4.80 \mathrm{~h}$, $\mathrm{SD}=2.72, Z=-4.020, p<0.001)$. Patients who had been rated as moderately, quite or very irritable $(N=72)$ had more elevated eTMT than those who were rated as slightly/not irritable $(F(2 / 120)=3.236, p<0.043)$. Similarly, patients with poor or very poor ability to focus/concentrate under lockdown $(N=59)$ had higher eTMT than patients with moderate or good concentration $(N=67)(F(1 / 122)=7.952$, $p<0.006)$. However, patients with more $(N=62)$ or less $(N=64)$ hyperactivity/restlessness did not significantly differ regarding eTMT $(F(1.122)=3.161, p<0.078)($ Fig. 3)

\section{Discussion}

In this sample of patients clinically referred for ADHD, a $42 \%$ increase in total media time was observed under lockdown according to parents' ratings. After the lockdown, i.e., after the return to school for most students, total media time decreased considerably, but did not completely return to pre-Corona levels. Parents reported a significant increase

Table 3 Problem behaviors and media related risks under lockdown in children ( $\leq 13$ years) and adolescents ( $\geq 14$ years)

\begin{tabular}{|c|c|c|c|c|c|c|c|c|}
\hline \multirow[b]{2}{*}{$\begin{array}{l}\text { I am concerned that my child } \\
\text { might... }\end{array}$} & \multicolumn{4}{|c|}{ Children $(N=66)(=100 \%)$} & \multicolumn{4}{|c|}{ Adolescents $(N=60)(=100 \%)$} \\
\hline & Not true & Slightly true & Quite true & Absolutely true & Not true & Slightly true & Quite true & Absolutely true \\
\hline ....be a victim of cyberbullying & 77.3 & 15.2 & 6.1 & 1.5 & 71.7 & 23.3 & 5.0 & 0.0 \\
\hline ... be a cyberbullying perpetrator & 87.9 & 9.1 & 1.5 & 1.5 & 83.3 & 16.7 & 0.0 & 0.0 \\
\hline $\begin{array}{l}\text {... be too careless with risks on } \\
\text { the internet (e.g., handling of } \\
\text { personel data, photos) }\end{array}$ & 57.6 & 37.9 & 3.0 & 1.5 & 56.7 & 26.7 & 13.3 & 3.3 \\
\hline $\begin{array}{l}\text {... play video games with harmful } \\
\text { or age-inappropriate content (e.g., } \\
\text { trivializing violence) }\end{array}$ & 63.6 & 30.3 & 4.5 & 1.5 & 38.3 & 48.8 & 8.3 & 5.0 \\
\hline $\begin{array}{l}\text {..visit problematic chatrooms } \\
\text { / chat groups (e.g., promoting } \\
\text { self-harm) }\end{array}$ & 80.3 & 13.3 & 3.0 & 3.0 & 60.0 & 31.7 & 8.3 & 0.0 \\
\hline $\begin{array}{l}\text {... watch films, series or clips with } \\
\text { harmful or age-inappropriate } \\
\text { content }\end{array}$ & 48.5 & 37.9 & 9.1 & 4.5 & 30.0 & 56.7 & 11.7 & 1.7 \\
\hline $\begin{array}{l}\text {... illegally download or download } \\
\text { or distribute prohibited content }\end{array}$ & 83.3 & 13.6 & 1.5 & 0 & 61.7 & 36.7 & 1.7 & 0 \\
\hline
\end{tabular}



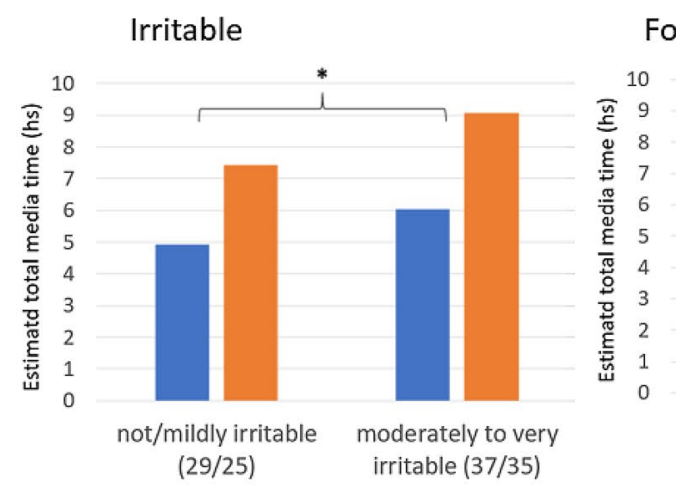

Focused/inattentive

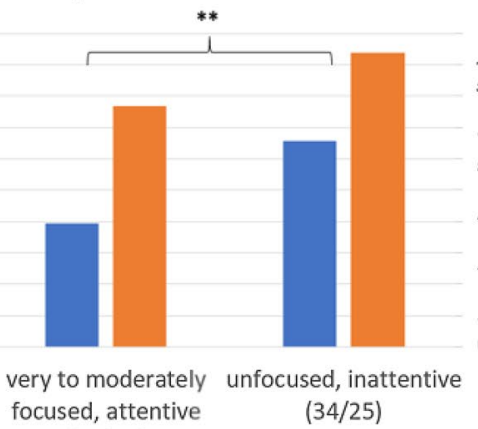

$(32 / 35)$
Fidgety/restless

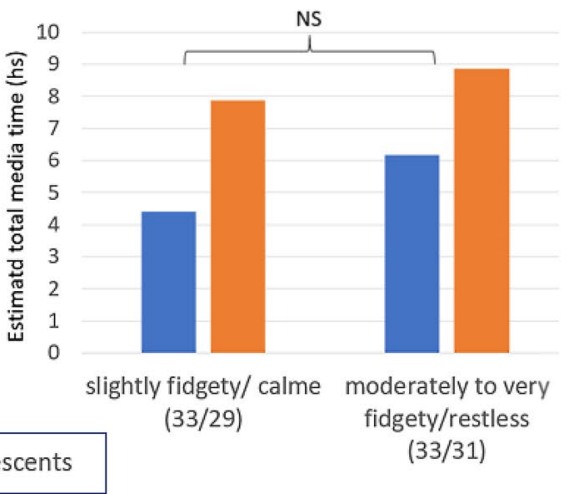

Fig. 3 Estimated total media time (hours) in subgroups of children and adolescents with higher versus lower irritability, attention/inattention, and hyperactivity/restlessness during the lockdown as rated by parents. Adolescents had significantly higher media times, but age- by subgroup interactions were not significant. Numbers in parentheses $=N$ (children/adolescents). $* p<0.05 ; * * p<0.01, N S$ non significant

\section{Limitations}

Some limitations of the study should be mentioned: first, all ratings of change are based on parents' retrospective evaluations and may, therefore, be biased. Second, we did not collect objective data on socio-economic status and cultural background. Parents indicated that their child had been referred to child and adolescent psychiatry for ADHD, but for a minority still in the diagnostic process, the diagnosis may not have been confirmed. Finally, all diagnostic categories were self-assessed.

\section{Conclusion}

As shown in the short literature summary, children, adolescents and young adults with ADHD are at risk of PUI. According to the present study on screen media use before, during and after the lockdown in spring 2020, total media time considerably increased during the lockdown in a sample of children and adolescents referred for ADHD to child and adolescent psychiatry, subsequently decreased after the easing of measures, but remained at a higher level than before the crisis. To the best of our knowledge, this is the first study to compare media related behavior before, during and after the lockdown in children and adolescents clinically referred for ADHD.

Funding Open Access funding provided by Universität Zürich.

Open Access This article is licensed under a Creative Commons Attribution 4.0 International License, which permits use, sharing, adaptation, distribution and reproduction in any medium or format, as long as you give appropriate credit to the original author(s) and the source, provide a link to the Creative Commons licence, and indicate if changes 
were made. The images or other third party material in this article are included in the article's Creative Commons licence, unless indicated otherwise in a credit line to the material. If material is not included in the article's Creative Commons licence and your intended use is not permitted by statutory regulation or exceeds the permitted use, you will need to obtain permission directly from the copyright holder. To view a copy of this licence, visit http://creativecommons.org/licenses/by/4.0/.

\section{References}

Andreassen CS, Torsheim T, Brunborg GS, Pallesen S (2012) Development of a Facebook addiction scale. Psychol Rep 110:501-517

Andreassen CS, Billieux J, Griffiths MD, Kuss DJ, Demetrovics Z, Mazzoni E, Pallesen S (2016) The relationship between addictive use of social media and video games and symptoms of psychiatric disorders: a large-scale cross-sectional study. Psychol Addict Behav 30:252

APA (2013) Diagnostic and statistical manual of mental disorders (DSM-5®). American Psychiatric Pub, New York

Asam El, Aiman MS, Terry P (2019) Problematic internet use and mental health among British children and adolescents. Addict Behav 90:428-436

Bacchini D, Affuso G, Trotta T (2008) Temperament ADHD and peer relations among schoolchildren: the mediating role of school bullying. Aggress Behav 34:447-459

Bányai F, Zsila Á, Király O, Maraz A, Elekes Z, Griffiths MD, Andreassen CS et al (2017) Problematic social media use: results from a large-scale nationally representative adolescent sample. PLOS ONE 12:e0169839

Barry CT, Sidoti CL, Briggs SM, Reiter SR, Lindsey RA (2017) Adolescent social media use and mental health from adolescent and parent perspectives. J Adolesc 61:1-11

Becker SP, Rosanna B, Caroline NC, Dvorsky MR, Marsh NP, Sciberras E, Langberg JM (2020) Remote learning during COVID-19: examining school practices, service continuation, and difficulties for adolescents with and without attention-deficit/hyperactivity disorder. J Adolesc Health. 67:769-777

Bioulac S, Arfi L, Bouvard MP (2008) Attention deficit/hyperactivity disorder and video games: a comparative study of hyperactive and control children. Eur Psychiatry 23:134-141

Blanca MJ, Alarcón R, Arnau J, Bono R, Bendayan R (2017) Non-normal data: is ANOVA still a valid option? Psciothema 29:552-557

Bobo E, Lin L, Acquaviva E, Caci H, Franc H, Gamon L, Picot MC et al. (2020) How do children and adolescents with Attention Deficit Hyperactivity Disorder (ADHD) experience lockdown during the COVID-19 outbreak? L'encephale

Boer M, Stevens G, Finkenauer C, van den Eijnden R (2020) Attention deficit hyperactivity disorder-symptoms, social media use intensity, and social media use problems in adolescents: Investigating directionality. Child Dev 91:e853-e865

Brand M, Young KS, Laier C, Wölfling K, Potenza MN (2016) Integrating psychological and neurobiological considerations regarding the development and maintenance of specific Internet-use disorders: an Interaction of Person-Affect-Cognition-Execution (I-PACE) model. Neurosci Biobehav Rev 71:252-266

Cabral J (2008) Is generation Y addicted to social media. Future Child 2:5-14

Carli V, Durkee T, Wasserman D, Hadlaczky G, Roman Despalins E, Kramarz CW et al (2013) The association between pathological internet use and comorbid psychopathology: a systematic review. Psychopathology 46:1-13

Cassuto H, Ben-Simon A, Berger I (2013) Using environmental distractors in the diagnosis of ADHD. Front Hum Neurosci 7:805
Ceranoglu TA (2018) Inattention to problematic media use habits: Interaction between digital media use and attention-deficit/ hyperactivity disorder. Child Adolesc Psychiatr Clin 27:183-191

Chan PA, Rabinowitz T (2006) A cross-sectional analysis of video games and attention deficit hyperactivity disorder symptoms in adolescents. Ann Gen Psychiatry 5:16

Chang C-H, Chang Y-C, Cheng H, Tzang R-F (2020) Treatment efficacy of internet gaming disorder with attention deficit hyperactivity disorder and emotional dysregulaton. Int J Neuropsychopharmacol 23:349-355

Chen Y-L, Chen S-H, Gau S-F (2015) ADHD and autistic traits, family function, parenting style, and social adjustment for Internet addiction among children and adolescents in Taiwan: a longitudinal study. Res Dev Disabil 39:20-31

Chen L, Lyu H, Yang T, Wang Y, Luo J (2020) In the eyes of the beholder: sentiment and topic analyses on social media use of neutral and controversial terms for COVID-19. arXiv preprint arXiv: 2004. 10225

Christakis DA, Moreno MA (2009) Trapped in the net: will internet addiction become a 21st-century epidemic? Arch Pediatr Adolesc Med 163:959-960

Cortese S, Asherson P, Sonuga-Barke E, Banaschewski T, Brandeis D, Buitelaar J, Coghill D et al (2020) ADHD management during the COVID-19 pandemic: guidance from the European ADHD Guidelines Group. Lancet Child Adolesc Health $4: 412-414$

Darvesh N, Radhakrishnan A, Lachance CC, Nincic V, Sharpe JP, Ghassemi M, Straus SE et al (2020) Exploring the prevalence of gaming disorder and Internet gaming disorder: a rapid scoping review. Syst Rev 9:1-10

Dawson AE, Wymbs BT, Evans SW, DuPaul GJ (2019) Exploring how adolescents with ADHD use and interact with technology. J Adolesc 71:119-137

Dell'Osso B, Hadley S, Allen A, Baker B, Chaplin WF, Hollander E (2008) Escitalopram in the treatment of impulsive-compulsive internet usage disorder: an open-label trial followed by a doubleblind discontinuation phase. J Clin Psychiatry 69:452-456

Den Eijnden V, Regina JJM, Lemmens JS, Valkenburg PM (2016) The social media disorder scale. Comput Hum Behav 61:478-487

Didden R, Scholte RHJ, Korzilius H, De Moor JMH, Vermeulen A, O'Reilly M, Lang R et al (2009) Cyberbullying among students with intellectual and developmental disability in special education settings. Dev Neurorehabil 12:146-151

Dullur P, Krishnan V, Diaz AM (2021) A systematic review on the intersection of attention-deficit hyperactivity disorder and gaming disorder. J Psychiatr Res 133:212-222

Durkee T, Kaess M, Carli V, Parzer P, Wasserman C, Floderus B, Apter A et al (2012) Prevalence of pathological internet use among adolescents in Europe: demographic and social factors. Addiction 107:2210-2222

Enagandula R, Singh S, Adgaonkar GW, Subramanyam AA, Kamath RM (2018) Study of internet addiction in children with attentiondeficit hyperactivity disorder and normal control. Ind Psychiatry J 27:110

Fauth-Bühler M, Mann K (2017) Neurobiological correlates of internet gaming disorder: Similarities to pathological gambling. Addict Behav 64:349-356

Frost RL, Rickwood DJ (2017) A systematic review of the mental health outcomes associated with Facebook use. Comput Hum Behav 76:576-600

Gámez-Guadix M, Borrajo E, Almendros C (2016) Risky online behaviors among adolescents: longitudinal relations among problematic internet use, cyberbullying perpetration, and meeting strangers online. J Behav Addict 5:100-107 
Gentile DA, Bailey K, Bavelier D, Brockmyer JF, Cash H, Coyne SM, Doan A et al (2017) Internet Gaming Disorder in children and adolescents. Pediatrics 140:S81-S85

Gorucu Aydin R, Gurkan CK, Canli M, Kilic HT (2020) The effects of cyber bullying or victimization behaviors on social reciprocity and online cognition of adolescents with attention-deficit/hyperactivity disorder. Psychiatry Behav Sci 10:63-71

Grüsser SM, Thalemann R, Griffiths MD (2006) Excessive computer game playing: evidence for addiction and aggression? Cyberpsychol Behav 10:290-292

Guessoum SB, Jonathan L, Rahmeth R, Emilie C, Sevan M, Laelia B, Marie RM (2020) Adolescent psychiatric disorders during the COVID-19 pandemic and lockdown. Psychiatry Res 291:113264

Gul H, Solmaz EY, Gul A, Oner O (2018) Facebook overuse and addiction among Turkish adolescents: are ADHD and ADHDrelated problems risk factors? Psychiatry Clin Psychopharmacol 28:80-90

Ha JH, Yoo HJ, Cho IH, Chin B, Shin D, Kim JH (2006) Psychiatric comorbidity assessed in Korean children and adolescents who screen positive for Internet addiction. J Clin Psychiatry 67:821-826

Han DH, Lee YS, Na C, Ahn JY, Chung US, Daniels MA, Haws CA et al (2009) The effect of methylphenidate on Internet video game play in children with attention-deficit/hyperactivity disorder. Compr Psychiatry 50:251-256

Harty SC, Miller CJ, Newcorn JH, Halperin JM (2009) Adolescents with childhood ADHD and comorbid disruptive behavior disorders: aggression, anger, and hostility. Child Psychiatry Hum Dev 40:85-97

Heiman T, Olenik-Shemesh D, Eden S (2015) Cyberbullying involvement among students with ADHD: relation to loneliness, selfefficacy and social support. Eur J Spec Needs Educ 30:15-29

Ho RC, Zhang MWB, Tsang TY, Toh AH, Pan F, Yanxia Lu, Cheng C et al (2014) The association between internet addiction and psychiatric co-morbidity: a meta-analysis. BMC Psychiatry 14:1-10

Ioannidis K, Treder MS, Chamberlain SR, Kiraly F, Redden SA, Stein DJ, Lochner C et al (2018) Problematic internet use as an agerelated multifaceted problem: evidence from a two-site survey. Addict Behav 81:157-166

Jones C, Scholes L, Johnson D, Katsikitis M, Carras MC (2014) Gaming well: links between videogames and flourishing mental health. Front Psychol 5:260

Kaess M, Durkee T, Brunner R, Carli V, Parzer P, Wasserman C, Sarchiapone $M$ et al (2014) Pathological Internet use among European adolescents: psychopathology and self-destructive behaviours. Eur Child Adolesc Psychiatry 23:1093-1102

Karaiskos D, Tzavellas E, Balta G, Paparrigopoulos T (2010) P02-232Social network addiction: a new clinical disorder? Eur Psychiatry 25:1-1

King DL, Potenza MN (2019) Not playing around: gaming disorder in the International Classification of Diseases (ICD-11). J Adolesc Health 64:5-7

King DL, Delfabbro PH, Billieux J, Potenza MN (2020) Problematic online gaming and the COVID-19 pandemic. J Behav Addict 9:184-186

Király O, Potenza MN, Stein DJ, King DL, Hodgins DC, Saunders JB, Griffiths MD et al (2020) Preventing problematic internet use during the COVID-19 pandemic: consensus guidance. Compr Psychiatry 152180

Ko C-H, Yen J-Y (2020) Impact of COVID-19 on gaming disorder: monitoring and prevention. J Behav Addict 9:187-189

Ko C-H, Yen J-Y, Chen C-C, Chen S-H, Yen C-F (2005) Proposed diagnostic criteria of Internet addiction for adolescents. J Nerv Ment Dis 193:728-733

Ko C-H, Yen J-Y, Chen C-S, Yeh Y-C, Yen C-F (2009) Predictive values of psychiatric symptoms for internet addiction in adolescents: a 2-year prospective study. Arch Pediatr Adolesc Med 163:937-943

Kowalski RM, Limber SP (2013) Psychological, physical, and academic correlates of cyberbullying and traditional bullying. J Adolesc Health 53:S13-S20

Kowalski RM, Limber SP, Agatston PW (2012) Cyberbullying: Bullying in the digital age. Wiley, Amsterdam

Kubey RW, Lavin MJ, Barrows JR (2001) Internet use and collegiate academic performance decrements: early findings. J Commun $51: 366-382$

Lenhart A, Ling R, Campbell S, Purcell K (2010) Teens and mobile phones: text messaging explodes as teens embrace it as the centerpiece of their communication strategies with friends. Pew Internet and American Life Project

Leung L (2004) Net-generation attributes and seductive properties of the internet as predictors of online activities and internet addiction. Cyberpsychol Behav 7:333-348

Liu T, Potenza MN (2007) Problematic internet use: clinical implications. CNS Spectr 12:453-466

Machimbarrena JM, Calvete E, Fernández-González L, ÁlvarezBardón A, Álvarez-Fernández L, González-Cabrera J (2018) Internet risks: an overview of victimization in cyberbullying, cyber dating abuse, sexting, online grooming and problematic internet use. Int J Environ Res Public Health 15:2471

Mazurek MO, Engelhardt CR (2013) Video game use in boys with autism spectrum disorder ADHD, or typical development. Pediatrics 132:260-266

McElroy SL, Nelson EB, Welge JA, Kaehler L, Keck PE Jr (2008) Olanzapine in the treatment of pathological gambling: a negative randomized placebo-controlled trial. J Clin Psychiatry 69:433-440

Mérelle S, Kleiboer A, Schotanus M, Cluitmans TLM, Waardenburg CM, Kramer D, Van de Mheen D et al (2017) Which healthrelated problems are associated with problematic video-gaming or social media use in adolescents? Clin Neuropsychiatry J Treat Eval 14:11-19

Montag C, Elhai JD (2020) Discussing digital technology overuse in children and adolescents during the COVID-19 pandemic and beyond: on the importance of considering affective neuroscience theory. Addict Behav Rep 12:100313

Moreno C, Wykes T, Galderisi S, Nordentoft M, Crossley N, Jones N, Cannon M et al (2020) How mental health care should change as a consequence of the COVID-19 pandemic. Lancet Psychiatry $7: 813-824$

Nikkelen SWC, Valkenburg PM, Huizinga M, Bushman BJ (2014) Media use and ADHD-related behaviors in children and adolescents: a meta-analysis. Dev Psychol 50:2228

Nonweiler J, Rattray F, Baulcomb J, Happé F, Absoud M (2020) Prevalence and associated factors of emotional and behavioural difficulties during COVID-19 pandemic in children with neurodevelopmental disorders. Children 7:128

Panagiotidi M, Overton P (2018) The relationship between internet addiction, attention deficit hyperactivity symptoms and online activities in adults. Compr Psychiatry 87:7-11

Paulus FW, Ohmann S, von Gontard A, Popow C (2018) Internet gaming disorder in children and adolescents: a systematic review. Dev Med Child Neurol 60:645-659

Petry NM, Rehbein F, Gentile DA, Lemmens JS, Rumpf H-J, Mößle $\mathrm{T}$, Bischof $\mathrm{G}$ et al (2014) An international consensus for assessing internet gaming disorder using the new DSM-5 approach. Addiction 109:1399-1406

Rehbein F, Kliem S, Baier D, Mößle T, Petry NM (2015) Prevalence of internet gaming disorder in German adolescents: diagnostic contribution of the nine DSM-5 criteria in a state-wide representative sample. Addiction 110:842-851 
Restrepo A, Scheininger T, Clucas J, Alexander L, Salum GA, Georgiades K, Paksarian D et al (2020) Problematic internet use in children and adolescents: associations with psychiatric disorders and impairment. BMC Psychiatry 20:1-11

Rosen LD, Lim AF, Julie Felt L, Carrier M, Cheever NA, Lara-Ruiz JM, Mendoza JS et al (2014) Media and technology use predicts ill-being among children, preteens and teenagers independent of the negative health impacts of exercise and eating habits. Comput Hum Behav 35:364-375

Rosenberg KP, Laura CF (2014) Behavioral addictions: criteria, evidence, and treatment. Academic Press, New York

Rubia K (2018) Cognitive neuroscience of attention deficit hyperactivity disorder (ADHD) and its clinical translation. Front Hum Neurosci 12:100

Rumpf H-J, Vermulst AdA, Bischof A, Kastirke N, Gürtler D, Bischof G, Meerkerk G-J et al (2014) Occurence of internet addiction in a general population sample: a latent class analysis. Eur Addict Res 20:159-166

Sattar P, Ramaswamy S (2004) Internet gaming addiction. Can J Psychiatry 49:869-870

Sciberras E, Patel P, Stokes MA, Coghill D, Middeldorp CM, Bellgrove MA, Becker SP et al (2020) Physical health, media use, and mental health in children and adolescents with ADHD during the COVID-19 pandemic in australia. J Attent Disord 1087054720978549

Settanni M, Marengo D, Fabris MA, Longobardi C (2018) The interplay between ADHD symptoms and time perspective in addictive social media use: a study on adolescent Facebook users. Child Youth Serv Rev 89:165-170

Shen Y, Wang L, Huang C, Guo J, De Leon SA, Lu JP, Luo X et al (2020) Sex differences in prevalence, risk factors and clinical correlates of internet addiction among Chinese College Students. $J$ Affect Disord

Shapira NA, Goldsmith TD, Keck Jr PE, Khosla UM, McElroy SL (2000) Psychiatric features of individuals with problematic internet use. J Affect Disord 57:267-272

Shapira NA, Lessig MC, Goldsmith TD, Szabo ST, Lazoritz M, Gold MS, Stein DJ (2003) Problematic internet use: proposed classification and diagnostic criteria. Depress Anxiety 17:207-216

Shea B, Wiener J (2003) Social exile: the cycle of peer victmization for boys with ADHD. Can J Sch Psychol 18:55-90

Snodgrass JG, Lacy MG, Dengah HJF II, Eisenhauer S, Batchelder G, Cookson RJ (2014) A vacation from your mind: problematic online gaming is a stress response. Comput Hum Behav $38: 248-260$

Spada MM (2014) An overview of problematic internet use. Addict Behav 39:3-6

Stavropoulos V, Adams BLM, Beard CL, Dumble E, Trawley S, Gomez R, Pontes HM (2019) Associations between attention deficit hyperactivity and internet gaming disorder symptoms: is there consistency across types of symptoms, gender and countries? Addict Behav Rep 9:100158

Stavropoulos V, Baynes KL, O'Farrel DL, Gomez R, Mueller A, Yucel M, Griffiths M (2020) Inattention and disordered gaming: does culture matter? Psychiatr Q 91:1-16

Stevens MWR, King DL, Dorstyn D, Delfabbro PH (2019) Cognitivebehavioral therapy for Internet gaming disorder: a systematic review and meta-analysis. Clin Psychol Psychother 26:191-203
Suter L, Gregor W, Jael B, Céline K, Isabel W, Daniel S (2018) JAMES: Jugend, Aktivitäten, Medien-Erhebung Schweiz

Thomasius R (2020) Riskante und pathologische Nutzung von Games und sozialen Medien durch Kinder und Jugendliche nach Kriterien des ICD-11 und Einfluss des COVID-19-Lockdowns auf Medienzeiten in deutschen Familien. Accessed DAK Gesundheit 2020

Tokunaga RS (2010) Following you home from school: a critical review and synthesis of research on cyberbullying victimization. Comput Hum Behav 26:277-287

Vigna-Taglianti F, Brambilla R, Priotto B, Angelino R, Cuomo GianLuca, Diecidue R (2017) Problematic internet use among high school students: prevalence, associated factors and gender differences. Psychiatry Res 257:163-171

Wang B-Q, Yao N-q, Zhou X, Liu J, Lv Z-T (2017) The association between attention deficit/hyperactivity disorder and internet addiction: a systematic review and meta-analysis. BMC Psychiatry 17:260

Weinstein A, Lejoyeux M (2020) Neurobiological mechanisms underlying internet gaming disorder. Dialogues Clin Neurosci 22:113

WHO (2016) Gaming disorder, predominantly offline. ICD-11 Beta Draft (Foundation)

Werling AM, Walitza S, Grünblatt E, Drechsler R (submitted) Media use before, during and after COVID-19 lockdown in a clinically referred sample in child and adolescent psychiatry: Results of an online survey in Switzerland

Yao Y-W, Potenza MN, Zhang J-T (2017) Internet gaming disorder within the DSM-5 framework and with an eye toward ICD-11. Am J Psychiatry 174:486-487

Young KS (1998a) Caught in the net: How to recognize the signs of internet addiction-and a winning strategy for recovery. Wiley, Amsterdam

Young KS (1998b) Internet addiction: the emergence of a new clinical disorder. Cyberpsychol Behav 1:237-244

Young KS (2007) Cognitive behavior therapy with Internet addicts: treatment outcomes and implications. Cyberpsychol Behav 10:671-679

Young KS (2011) CBT-IA: the first treatment model for internet addiction. J Cogn Psychother 25:304-312

Yu JJ, Kim H, Hay I (2013) Understanding adolescents' problematic internet use from a social/cognitive and addiction research framework. Comput Hum Behav 29:2682-2689

Zajac K, Ginley MK, Chang R (2020) Treatments of internet gaming disorder: a systematic review of the evidence. Expert Rev Neurother 20:85-93

Zhang J, Shuai L, Hui Yu, Wang Z, Meihui Qiu LuLu, Cao X et al (2020) Acute stress, behavioural symptoms and mood states among school-age children with attention-deficit/hyperactive disorder during the COVID-19 outbreak. Asian J Psychiatr 51:102077

Publisher's Note Springer Nature remains neutral with regard to jurisdictional claims in published maps and institutional affiliations. 